\title{
Low temperature soot oxidation via the melting process of alkaline salts
}

\author{
D. Hirabayashi, H. Hashikawa \& K. Suzuki \\ EcoTopia Science Institute, Nagoya University, Japan
}

\begin{abstract}
We investigated low temperature soot oxidation mechanisms using several kinds of alkaline salts $\left(\mathrm{LiCO}_{3}, \mathrm{LiCl}, \mathrm{LiNO}_{3}, \mathrm{~K}_{2} \mathrm{CO}_{3}, \mathrm{KCl}, \mathrm{KNO}_{3}, \mathrm{Na}_{2} \mathrm{CO}_{3}, \mathrm{NaCl}\right.$ and $\mathrm{NaNO}_{3}$ ). Soot oxidation activity was evaluated by $\mathrm{CO}, \mathrm{CO}_{2}$ formation rate during combustion of a simulated soot through a temperature programmed oxidation experiments under simulated air conditions $\left(\mathrm{O}_{2}\right.$ concentration $=10$ $\mathrm{vol} \%$, total gas flow rate $=200 \mathrm{ml} \mathrm{min}^{-1}$, soot $=20 \mathrm{mg}, \gamma$-alumina powder $=340$ $\mathrm{mg}$ ) by using an FID-GC with methanizer. In the case of soot oxidation without molten salts, the TPO profile showed a single peak for $\mathrm{CO}, \mathrm{CO}_{2}$ formation around $770 \mathrm{~K}$. On the other hand, in the case with nitrate-based alkaline salts $\left(\mathrm{LiNO}_{3}, \mathrm{KNO}_{3}\right.$ and $\left.\mathrm{NaNO}_{3} ; 100 \mathrm{mg}\right)$, a single or a multiple peak consisting of two independent tops were observed in the lower temperature range (450-750 $\mathrm{K})$. Visible observation using an optical microscope revealed the characteristic mechanisms with some liquid phase contributions by melting and fluidization of alkaline salts. These processes could enhance the soot oxidation in low temperature ranges. Findings also proposed that the direct reaction between carbon and nitrate-based alkaline salts which involved into oxidation mechanisms at 450-650 K.
\end{abstract}

Keywords: soot oxidation, alkaline salts, oxidation mechanism.

\section{Introduction}

Soot particles emitted from diesel engines cause increasing attention due to their probable negative impact on the human respiratory system. Therefore, during the past decade, intensified techniques and methods have been made to reduce soot emissions. It is unlikely that it will be possible to meet future particle emission standards without the use of aftertreatment devices such as the diesel particulate 
filter (DPF). The filters combined with a heat-regeneration system have been suggested for the purpose. However this technology has a problem in reliability of the regeneration. Severe thermal shock cracking of the filter structure can be caused by excessive high temperature during regeneration, and the heat loss for the regeneration operation is too much to reduce the fuel merits of diesel engines. Thus, catalytic oxidation system is currently more promising for the continuous regeneration system. The merits with this technology are low energy (fuel) consumption, low recycle frequency, and high reliability for the system operation. The performance of DPFs is strongly dependent on the oxidation rate, and requires some more improvements to ensure the future strict standards.

Recently, some molten salts have been proposed as a good candidate catalyst or an effective promoter for soot oxidation, since higher combustion rate can be established at low temperature. Setten et al. investigated several molten salts, based on eutectic mixtures of $\mathrm{Cs}_{2} \mathrm{O}, \mathrm{V}_{2} \mathrm{O}_{4}, \mathrm{MoO}_{3}$ and $\mathrm{Cs}_{2} \mathrm{SO}_{4}$ [1-3]. These molten salts showed higher combustion rate at low temperature $(650 \mathrm{~K})$ due to ensuring the 'close contact' between catalyst and soot components by liquid phase contribution. Nitrate group alkaline salts have large possibility to be a better catalyst for the removal soot at lower temperatures [4]. This group exhibits lower melting points and higher combustion rate in a wider temperature range. Sakakibara et al. demonstrate that the nitrate group molten salts promote the soot oxidation 533-573 K, and, above all, the $\mathrm{LiNO}_{3}$ was most effective. The performance of such molten salt type catalysts also seems to be strongly dependent on the contact between solid and solid, however a more detailed understanding about interaction between soot component and molten phase, particularly the chemical role of the molten phase during soot oxidation process, are required.

In this paper, TPO for soot oxidation with three series of alkaline salts; carbonate, chloride and nitrate $\left(\mathrm{LiCO}_{3}, \mathrm{LiCl}, \mathrm{LiNO}_{3}, \mathrm{~K}_{2} \mathrm{CO}_{3}, \mathrm{KCl}, \mathrm{KNO}_{3}\right.$, $\mathrm{Na}_{2} \mathrm{CO}_{3}, \mathrm{NaCl}$ and $\mathrm{NaNO}_{3}$ ) were investigated. These TPO profiles with alkaline salts were compared with those without alkaline salt. Further, combustion experiments were performed using optical microscope with heating stage was achieved to clarify the detail interaction between soot and molten phase of alkaline salts.

\section{Experimental}

\subsection{Sample preparation}

Nine alkaline salts studied were regent powders of $\mathrm{LiCO}_{3}, \mathrm{LiCl}, \mathrm{LiNO}_{3}, \mathrm{~K}_{2} \mathrm{CO}_{3}$, $\mathrm{KCl}, \mathrm{KNO}_{3}, \mathrm{Na}_{2} \mathrm{CO}_{3}, \mathrm{NaCl}$ and $\mathrm{NaNO}_{3}$ (Wako Pure Chemicals Industries, Ltd.). The mixture of two molten salts, $\mathrm{KNO}_{3}-\mathrm{LiNO}_{3}$ was also tested. The mixtures were physically grounded and preheated in a crucible enough to fuse both nitrate phases. The melting points of these salts determined by TG/DTA are listed in Table 1.

A fine activated carbon powder consisted of amorphous carbon (Wako Pure Chemical Industries, Ltd.,) was used as the simulated soot. Salt samples were 
mixed with the soot in the mixing weight ratio of $2: 1$, and then grounded in a mortar followed by drying by an electrical oven. The obtained samples were carefully mixed with $\gamma$-alumina powder $\left(d_{p}=75-212 \mu \mathrm{m}\right)$ with a spatula at a ratio of $3: 20$. This $\gamma$-alumina powder was for a support to avoid a pressure loss and a fluxion of molten salts during experimental operations.

Table 1: $\quad$ Melting temperatures of the alkaline salts.

\begin{tabular}{c|c|c}
\hline Group & Samples & Melting temperature / K \\
\hline \hline \multirow{3}{*}{ Carbonate group } & $\mathrm{Li}_{2} \mathrm{CO}_{3}$ & 999 \\
& $\mathrm{~K}_{2} \mathrm{CO}_{3}$ & 985 \\
& $\mathrm{Na}_{2} \mathrm{CO}_{3}$ & 1174 \\
\hline \multirow{3}{*}{ Chloride group } & $\mathrm{LiCl}$ & 883 \\
& $\mathrm{KCl}$ & 1044 \\
& $\mathrm{NaCl}$ & 877 \\
\hline \multirow{3}{*}{ Nitrate group } & $\mathrm{LiNO}_{3}$ & 528 \\
& $\mathrm{KNO}_{3}$ & 607 \\
& $\mathrm{NaNO}_{3}$ & 579 \\
& $\mathrm{LiNO}_{3}+\mathrm{KNO}_{3}$ & 407 \\
\hline
\end{tabular}

\subsection{Evaluation of soot combustion}

The soot combustion was achieved by employing a temperature-programmed oxidation (TPO) method with a conventional fixed bed reactor. A $460 \mathrm{mg}$ of the mixture was loaded into the U-type quartz reactor $(8 \mathrm{~mm}$ in diameter, $c a .15 \mathrm{~mm}$ in bed height). For soot combustion experiments, the reactor temperature was elevated slowly at heating rate of $0.6,1.0,3.0$ and $6.0 \mathrm{~K} / \mathrm{min}$ from 400 to $800 \mathrm{~K}$. An $\mathrm{O}_{2} / \mathrm{He}$ gas flow $\left(\mathrm{O}_{2}: 10\right.$ vol\%, He: balance) was fed into the reactor at a constant rate of $200 \mathrm{ml} / \mathrm{min}$. The outlet gas from the reactor was monitored by an FID gas chromatograph (Shimadzu, GC8APF) equipped with a methanizer (GL science, MT221) to measure the concentration of $\mathrm{CO}$ and $\mathrm{CO}_{2}$ in the flow. Soot combustion rate $\left(R_{\text {comb }}\right)$ and $\mathrm{CO}_{2} / \mathrm{CO}$ formation rates $\left(r_{\mathrm{CO} 2} / r_{\mathrm{CO}}\right)$ were defined as following equations (6)-(8):

$$
\begin{gathered}
R_{\text {comb }}[1 / \mathrm{s}]=\frac{r_{\mathrm{CO}_{2}}[\mathrm{~mol} / \mathrm{s}]+r_{\mathrm{CO}}[\mathrm{mol} / \mathrm{s}]}{W_{0, \text { soot }}[\mathrm{g}]} \cdot M w_{C} \\
r_{\mathrm{CO}_{2}}[\mathrm{~mol} / \mathrm{s}]=\frac{C_{\mathrm{CO}_{2}}[\mathrm{ppm}] \cdot \mathrm{F}_{\text {total }}[\mathrm{l} / \mathrm{s}]}{22.4 \times 10^{-6}} \\
r_{\mathrm{CO}}[\mathrm{mol} / \mathrm{s}]=\frac{C_{\mathrm{CO}}[\mathrm{ppm}] \cdot \mathrm{F}_{\text {total }}[\mathrm{l} / \mathrm{s}]}{22.4 \times 10^{-6}}
\end{gathered}
$$

where $W_{0, \text { soot }}$ and $M w_{C}$ are initial weight of the soot and molecular weight of carbon, respectively. $C_{\mathrm{CO} 2}$ and $C_{\mathrm{CO}}$ are concentrations of $\mathrm{CO}_{2}$ and $\mathrm{CO}$ 
determined by gas chromatograph, $F_{\text {total }}$ is the total gas flow rate of the outlet gas from the reactor.

\subsection{Visible observation of soot combustion upon heating}

A visible observation during soot combustion process with some alkaline salt was performed by means of an optical microscope system with heating stage which can be supplied air flow. In this system, the stage temperature can be controlled at heating rate of $6 \mathrm{~K} / \mathrm{min}$ by image furnace, and fast temperature control of stage was realized during the operations. In order to clarify the melting process of alkaline salts and the interaction of each phase during the combustion, an excess amount of the alkaline salt with a small amount of soot particles was spread on an alumina sample stage.

\section{Results and discussion}

\subsection{TPO profiles of soot combustion without alkaline salt}

Figure 1 shows $\mathrm{CO}_{2}$ and $\mathrm{CO}$ formation rates without alkaline salt as a function of temperature at a heating rate of $0.6 \mathrm{~K} / \mathrm{min}$ in $10 \mathrm{vol} \% \mathrm{O}_{2}$. Upon heating, the soot combustion with the $\mathrm{CO}_{2}$ and $\mathrm{CO}$ formation started around $600 \mathrm{~K}$ followed by a rapid increase with the oxidation rate. The $\mathrm{CO}_{2}$ and $\mathrm{CO}$ formation rates reached maximum values at $T_{\text {top }}=770 \mathrm{~K}$ for $\mathrm{CO}_{2}$ and at $T_{\text {top }}=780 \mathrm{~K}$ for $\mathrm{CO}$ and then decreased. These results showed that soot combustion without catalyst requires a high temperature to be decomposed. These peak profiles showed single peaks with a shoulder in the low temperature ranges. Previously, similar peaks were reported in the observation in the $\mathrm{CO}_{2}$ formation during TPO of several commercial carbons [5]. As reported in the literature, the combustion temperature strongly depended on the type of carbon, and the soot combustion

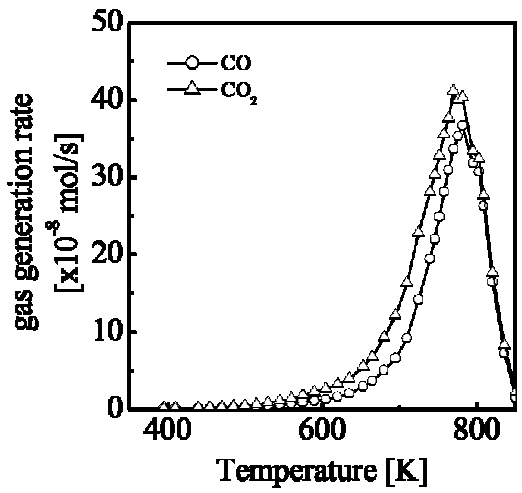

Figure 1: $\quad$ Experimental $\mathrm{CO}_{2}$ and $\mathrm{CO}$ formation rates during TPO in $10 \mathrm{vol} \%$ $\mathrm{O}_{2}$ with heating rate of $0.6 \mathrm{~K} / \mathrm{min}$. 
using diesel particulate can be burned at lower temperature $\left(T_{\text {top }}=823 \mathrm{~K}\right)$ than those characteristic of the other commercial carbons $\left(T_{t o p}=893-943 \mathrm{~K}\right)$. The activated carbon we used showed a similar single peak whose top were appeared at lower temperature during TPO operations.

\subsection{TPO profiles of soot combustion with alkaline salt}

The experimental soot combustion rates with several kinds of alkaline salts during TPO in $10 \mathrm{vol} \% \mathrm{O}_{2}$ with the heating rate of $0.6 \mathrm{~K} / \mathrm{min}$ are plotted in figure 2, 3, where carbonates and chlorides groups were displayed in figure 2, and nitrate group are shown in figure 3. The carbonate and chloride group presence showed single peaks with a shoulder or multiple peaks with tree tops in the TPO profiles. Temperatures of primary promotion peak were lower than those without presence of alkaline salts, and their peaks were varied with the kind of the alkaline salts in the temperature range from 600-800 K. By comparison of the primary promotion peak locations, the promotion effect show a clear dependence through a series, where the order of effects were $\mathrm{NaCO}_{3}<$ $\mathrm{KCO}_{3}<\mathrm{LiCO}_{3}$ and $\mathrm{NaCl}<\mathrm{KCl}<\mathrm{LiCl}$. However, the contribution of phase transition cannot be considered in this temperature range, since, as shown in table 1, the melting temperatures of the group are much higher than those of soot combustion. This might be ascribed to possible catalytic effects by alkaline metal sites (-Na, $-\mathrm{K},-\mathrm{Li})$ over the solid surfaces. Similar TPO shapes between $\mathrm{LiCl}$ and $\mathrm{LiCO}_{3}, \mathrm{KCl}$ and $\mathrm{KCO}_{3}, \mathrm{NaCl}$ and $\mathrm{NaCO}_{3}$ gives an evidence for this interpretation. Indeed TPO profile of $\mathrm{LiCO}_{3}$ showed a sharp primary peak that was very similar to $\mathrm{LiCl}$, although the peak top of $\mathrm{LiCO}_{3}$ was slightly sifted to lower temperature. Similarly, $\mathrm{K}_{2} \mathrm{CO}_{3}$ displayed almost the same peak compared with $\mathrm{KCl}$.

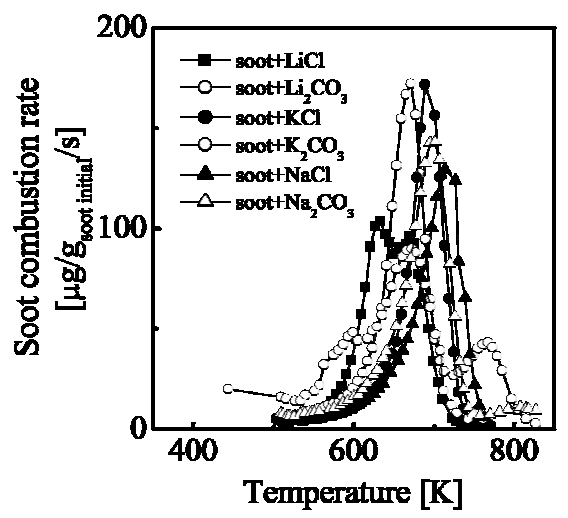

Figure 2: Experimental soot combustion rates for carbonates and chloride groups during TPO in $10 \mathrm{vol} \% \mathrm{O}_{2}$ with heating rate of $0.6 \mathrm{~K} / \mathrm{min}$.

Soot formation rates obtained with the presence of nitrate group was promoted in the lower temperature range $(450-750 \mathrm{~K})$ compared with those of 
carbonates and chlorides. The TPO profiles of alkaline nitrates are shown in figure 3. While, single peaks with a shoulder appeared in the profiles for $\mathrm{KNO}_{3}$ and $\mathrm{NaNO}_{3}$, a multiple peak with two tops were observed for $\mathrm{LiNO}_{3}$. The temperatures of the peak tops for $\mathrm{KNO}_{3}$ and $\mathrm{NaNO}_{3}$ were obtained at $T_{\text {top }}=640 \mathrm{~K}$ and $T_{\text {top }}=637 \mathrm{~K}$, respectively. Multiple peaks for $\mathrm{LiNO}_{3}$ had two tops at $T_{\text {top }}=573$ and $630 \mathrm{~K}$. It should be noted that all nitrate promoted the soot oxidation at the same temperature range of $600-750 \mathrm{~K}$, and they showed almost the same profiles during TPO. This means nitrate $\left(\mathrm{LiNO}_{3}, \mathrm{KNO}_{3}\right.$ and $\left.\mathrm{NaNO}_{3}\right)$ probably includes the same oxidation mechanism at higher temperature range above $600 \mathrm{~K}$. In this range, alkaline nitrates all used were completely changed to liquid phases. The liquid phase formation can contribute to establish the good contact between soot and its oxidizer during oxidation. However, $\mathrm{LiNO}_{3}$ had a secondary peak $\left(T_{t o p}=583 \mathrm{~K}\right)$ because of characteristic acceleration at lower temperature. Similar acceleration peak was also shown in the results of the mixture of nitrates $\left(\mathrm{LiNO}_{3}+\mathrm{KNO}_{3}\right)$. This peak was observed at the near temperature $\left(T_{\text {top }}=592 \mathrm{~K}\right)$ of the secondary peak of pure $\mathrm{LiNO}_{3}$, although the melting point of the mixture was much lower than those of the pure. Therefore, the low temperature mechanism for the $\mathrm{LiNO}_{3}$ mixture seemed to have no correlations with the physical properties of molten salts.

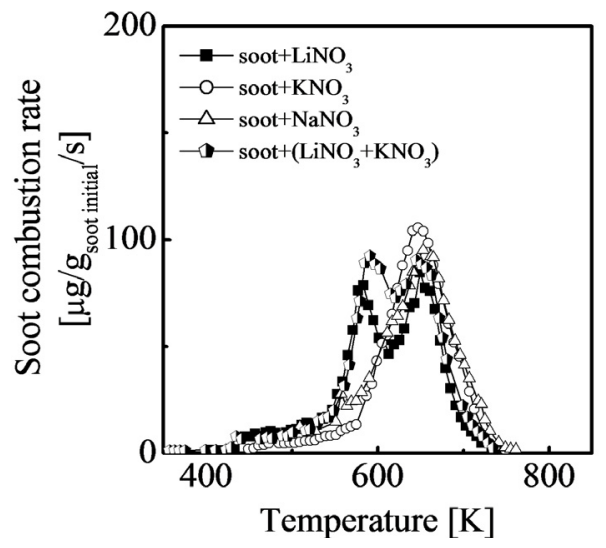

Figure 3: Experimental soot combustion rates for nitrate group during TPO in $10 \mathrm{vol} \% \mathrm{O}_{2}$ with heating rate of $0.6 \mathrm{~K} / \mathrm{min}$.

\subsection{Microscopic observation}

Figure 4 shows SEM images of simulated soot particles. While simulated soot particles consisted of agglomerated small primary particles whose particle size was $30-50 \mathrm{~nm}$, the size of agglomerated secondary particles were $300-1000 \mathrm{~nm}$ in diameter. It is well-known that the diesel particulate includes small particles with the particle size ranging from 10 to $1000 \mathrm{~nm}$.

The comparison among optical microscopic observations performed on the simulated soot and on the soot-alkaline salts mixtures. Pictures in figure 5 (a), 


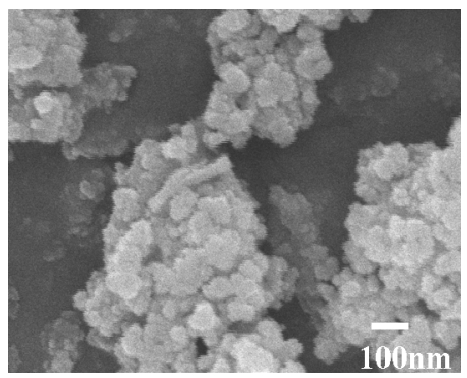

Figure 4: $\quad$ SEM image of simulated soot (activated carbon) particles.

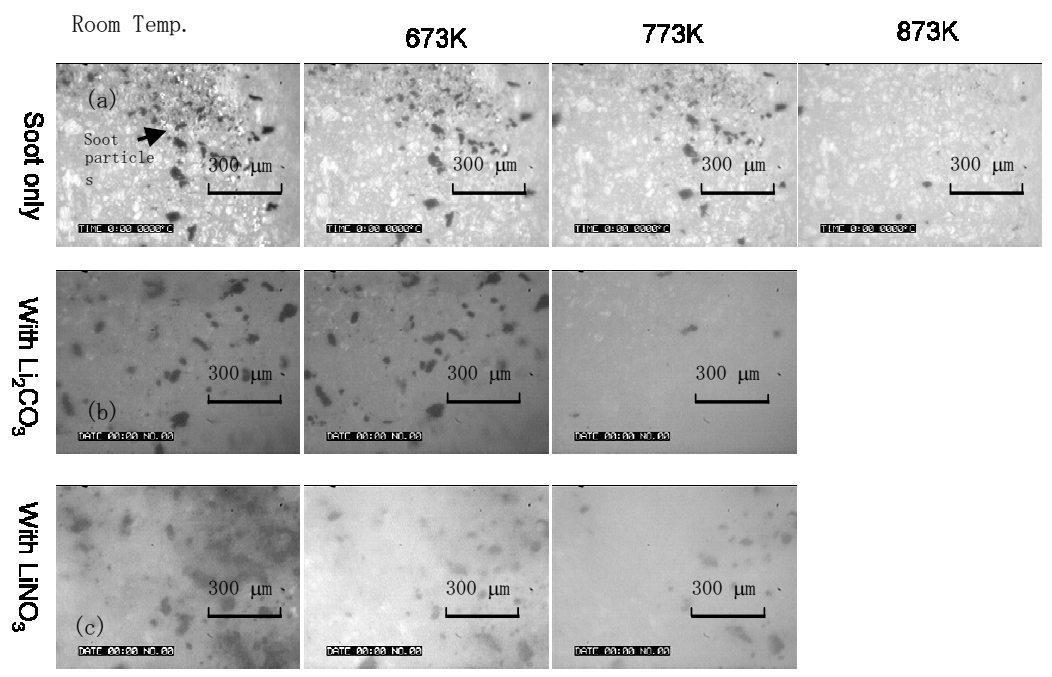

Figure 5: $\quad$ Pictures of soot particles observed by stereo optical microscope with in-situ heating stage in air flow $\left(\mathrm{O}_{2}: 20 \mathrm{vol} \%\right)$. Soot powder without mixing alkaline salts; (a), soot- $\mathrm{LiCO}_{3}$ (m.p. $999 \mathrm{~K}$ ) mixture; (b), soot-LiNO 3 (m.p. 528 K) mixture;(c).

referring to the soot combustion without salts, shows the process of particle shrinking with the increase of the temperature above $773 \mathrm{~K}$. Large soot particles could remain even at $873 \mathrm{~K}$. Similarly, concerning the soot- $\mathrm{LiCO}_{3}$ mixtures for pictures in figure 5 (b), the shrinking of particles was took place starting from $673 \mathrm{~K}$. This temperature is well agreed with the obtained $T_{\text {top }}$ value $(670 \mathrm{~K})$ for the peak top of TPO profile (see figure 2). On the other hand, the behaviour of soot-LiNO $\mathrm{L}_{3}$ mixture was quite different from others. No apparent change was observed below $500 \mathrm{~K}$. However the agglomeration of soot particles went into pieces as temperature increased up to melting temperature $(528 \mathrm{~K})$. Indeed, the picture for soot combustion with $\mathrm{LiNO}_{3}$ at $673 \mathrm{~K}$ in figure 5 (c) shows that the particles outlines became unclear compared with that at room temperature. This 
particle fragmentation with molten phase formation upon heating may be affect on the particle dispersion and soot combustion activity. The particles began to vibrate over melting temperature, and this vibration became harder with an increase of the temperature. This may contribute to the particle fragmentation and the particle dispersion into the molten phase.

Another finding for $\mathrm{LiNO}_{3}$ was the formation of bubbles along the interfaces between soot particles and molten salts, and this also become harder at 450-650 $\mathrm{K}$. The bubble formation could not be observed in the molten salts phase but observed only at interface as shown in figure 7 . This result implies the direct combustion of soot and $\mathrm{CO}_{2}$ and $\mathrm{CO}$ formation at the interface.

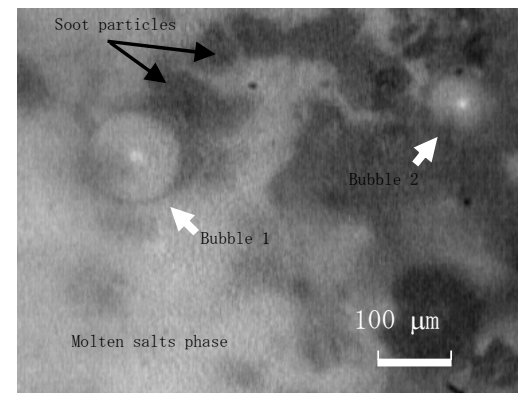

Figure 6: $\quad$ Picture of bubble formation observed at interface between soot particles and molten salts $\left(\mathrm{LiNO}_{3}\right)$ around $580 \mathrm{~K}$.

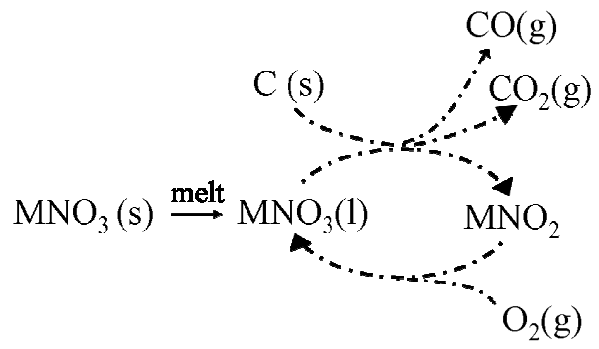

Figure 7: $\quad$ Proposed scheme of soot combustion with nitrate as observed by TPO.

\subsection{Low temperature soot combustion mechanisms with molten nitrate contribution}

Thus, in the case of nitrates, it is likely that the promotion effects of soot combustion with molten salts were not only based on the physical tight contact by forming a liquid phase. A plausible fundamental mechanic pathway of soot oxidation with nitrate according to both the TPO and microscope observation could be as sketched in figure 7 . There are two possible mechanisms for the promotion of the low temperature combustion. 
One is explained by chemical contribution of the nitrate to the oxidation pathway. Alkaline metal nitrates decompose into a nitrite with releasing oxygen in the high temperature region $(>873 \mathrm{~K})$ :

$$
\mathrm{MNO}_{3} \longrightarrow \mathrm{MNO}_{2}+1 / 2 \mathrm{O}_{2}
$$

where $\mathrm{M}$ represents alkaline metals $(\mathrm{M}=\mathrm{Li}, \mathrm{K}, \mathrm{Na})$. When the soot $(\mathrm{C})$ is involved in the system, following reaction proceeds at the low temperatures $(<700 \mathrm{~K})$ :

$$
\begin{gathered}
\mathrm{MNO}_{3}+1 / 2 \mathrm{C} \longrightarrow \mathrm{MNO}_{2}+1 / 2 \mathrm{CO}_{2} \\
\mathrm{MNO}_{3}+1 / 2 \mathrm{C} \longrightarrow \mathrm{MNO}_{2}+\mathrm{CO}
\end{gathered}
$$

Thermodynamically, nitrate $\left(\mathrm{MNO}_{2}\right)$ converted by above eqn. (4) and (5) is unstable at low temperatures, so that the nitrate $\left(\mathrm{MNO}_{3}\right)$ is reproduced as follows:

$$
\mathrm{MNO}_{2}+1 / 2 \mathrm{O}_{2} \longrightarrow \mathrm{MNO}_{3}
$$

Accordingly, the nitrate-nitrite cycle can be made for the soot catalytic oxidation with nitrate in the temperature region from 500-700K.

Another explanation, of course, is physical kinetic effects by formation of the molten phase. In the temperature range from 528-607 $\mathrm{K}, \mathrm{LiNO}_{3}, \mathrm{KNO}_{3}$ and $\mathrm{NaNO}_{3}$ appeared to involve in the combustion as the liquid phase. Note that almost the same oxidation curves were observed for any nitrates above $600 \mathrm{~K}$ in figure 3. This behaviour of TPO profiles can be explained by assuming the high contact of liquid phase with the soot: soot oxidation with liquid-solid interaction proceeds rapidly and uniformly with the increase of molten phase over melting temperature. The particle fragmentation with particle dispersion into the molten phase can also contribute to this mechanism. These may imply the significant reduction of activation energy in the soot combustion with nitrate (mentioned above as eqn. (5) and (6)). Particularly, $\mathrm{NiNO}_{3}$ and its mixture with $\mathrm{KNO}_{3}$ showed high combustion rates at lower temperatures $(<600 \mathrm{~K})$. Melting temperature of these nitrate were substantially smaller than those observed for other nitrates. Therefore, the lower melting temperature, the higher oxidation rates were observed at low temperature.

\section{Conclusions}

Alkaline salts shows $\mathrm{LiCO}_{3}, \mathrm{LiCl}, \mathrm{LiNO}_{3}, \mathrm{~K}_{2} \mathrm{CO}_{3}, \mathrm{KCl}, \mathrm{KNO}_{3}, \mathrm{Na}_{2} \mathrm{CO}_{3}, \mathrm{NaCl}$ and $\mathrm{NaNO}_{3}$ showed a significant promotion of the soot combustion at low temperatures. The promotion mechanisms depended on the kind of alkaline salts and the physicochemical properties. Chloride and carbonate group with comparatively high melting temperature showed a weak catalytic activity towards soot combustion based on the solid-solid contact between carbon and alkaline salts. The alkaline salts having common alkaline metals showed similar TPO profiles which have multiple peaks in the temperature range at $600-800 \mathrm{~K}$. Nitrate group with lower melting temperatures showed higher promotion effects towards soot combustion in the lower temperature range at 450-750 K. The promotion effects by nitrate were primary based on the formation of a molten 
phase. The formation of the molten phase affects on not only solid-liquid contact but also the particle fragmentation of soot. This physical effect could be established by the increase of the liquid mobility upon heating. The decrease of particle size and the higher contact is a meaningful possible mechanism significantly to enhance the soot combustion. Liquid phase of nitrate also contributed to a new pathway with a reaction on the soot surface. These characteristic reactions between soot and nitrate take place starting at lower temperature than typical soot oxidation with gas phase oxygen as oxidizer. The proof of this mechanism was given by the micro bubble formation at the interface between soot and molten phase at 450-650 K. For soot combustion with nitrate, a new mechanism with nitrate-nitrite cycle was proposed. This cycle can thermodynamically proceed with soot combustion at lower temperature than those of the typical carbon combustion.

\section{References}

[1] Jelles, S.J., van Setten, B.A.A.L., Makkee, M., \& Moulijin, J.A., Applied Catalysis B: Environmental, 21, pp.35-49, 1999.

[2] Saracco, G., Serra, Badini, C. \& Speccchia, V., Industrial \& Engineering Chemistry Research, 36, pp. 2051-2058, 1997.

[3] Ciambelli, P., Palma, V. \& Vaccaro, S., Catalysis Today, 17(1), pp.71-78, 1993.

[4] Sakakibara, Y., Kayama, T., \& Shinjoh, H., U. S. Patent Application 6777368, 2004.

[5] Fino, D., Russo, N., Badini, C., Saracco, G., \& Specchia, V., AIChE Journal, 49(8), pp. 2173-2180, 2003. 